\title{
Lactobacillus acidophilus/Streptococcus thermophilus/Bifidobacterium lactis/L. rhamnosus/B. longum/B. bifidum-based Probiotic Supplement
}

National Cancer Institute

\section{Source}

National Cancer Institute. Lactobacillus acidophilus/Streptococcus

thermophilus/Bifidobacterium lactis/L. rhamnosus/B. longum/B. bifidum-based Probiotic

Supplement. NCI Thesaurus. Code C103275.

A nutritional supplement containing probiotic cultures of Lactobacillus acidophilus (L.

acidophilus), L. rhamnosus Streptococcus thermophilus, Bifidobacterium lactis, (B. lactis),

B. longum and B. bifidum, with gastrointestinal ( $\mathrm{Gl}$ ) protective and immunomodulating activities. Upon oral administration, the bacteria in this probiotic supplement help maintain adequate colonization of the Gl tract and modulate the composition of the normal microflora. Upon colonization of the Gl tract, the probiotic bacteria form a protective barrier that helps maintain the integrity of the epithelial barrier. This will interfere with the attachment of pathogenic bacteria and other harmful substances, prevent inflammation and improve Gl function. 